\title{
The Experimental Investigation of Punching of the AM60 and AZ61 Magnesium Alloy Sheets by Using Varied Punch Shapes
}

\section{DOI:10.36909/jer.12813}

\author{
Harun Cuğ ${ }^{*}$, Shokri Saleh M. Khalifa*, Hakan Gürün ${ }^{*}$ \\ * Karabuk University, Department of Mechanical Engineering, Karabuk, Turkey \\ ** Gazi University, Department of Manufacturing Engineering, Ankara, Turkey
}

*Email: hgurun@gazi.edu.tr; Corresponding Author.

\begin{abstract}
The using of magnesium alloys for industrial sheet metal part production has become increasingly common in recent years. This research aims to characterize the effects of the cutting-edge shapes of the punches on the blanking forces and the sheared edge qualities in the blanking/piercing operations of magnesium alloy sheets. Magnesium sheets (AM60 and AZ61) were produced by casting and rolling processes. AM60 and AZ61 Mg alloys produced by casting were rolled by using two different speeds, $2.5 \mathrm{~m} / \mathrm{min}$ and $7.5 \mathrm{~m} / \mathrm{min}$. Material thickness was adjusted to three $\mathrm{mm}$ in the rolling process. Blanking tests were carried out on a die-set and hydraulic press by varying shaped punches. In the experimental studies, flat-ended, concave shaped, and $16^{\circ}$ angled punches were used. A loadcell was fixed to the experimental setup to determine the blanking forces. The results showed that the AM60 alloy was more resistant to shearing than the AZ61. The lowest blanking force was obtained by use of the $16^{\circ}$ angled punch. It was determined that the using of flat-ended punches for blanking operations was more convenient according to the usage purpose of the parts while all three punches can be used for piercing operations.
\end{abstract}

Key words: AZ61, AM60, rolling, blanking, punch shape, blanking force 


\section{INTRODUCTION}

Magnesium and its alloy play an important role in engineering and industrial applications due to their light weight and recyclability. The density of magnesium is $36 \%$ lower than aluminum, 74\% lower than zinc, and 79\% lower than steel. Mg-Al-Zn alloys put forth more flexibility in terms of machinability and offer a favorable strength-ductility relationship in industrial applications. Adding the appropriate amounts of additives in the casting process can improve the properties of magnesium alloys including strength, castability, machinability, corrosion resistance, and weldability (Kumar et al., 2015). Mg alloys showed improvement in corrosion properties with the addition of $\mathrm{Fe}$ and $\mathrm{Mn}$ materials. Be and $\mathrm{Ca}$ on $\mathrm{Mg}-9 \mathrm{Al}-1 \mathrm{Zn}$ showed improvement in oxidation resistance at high temperatures because of the formation Be-reinforced compact $\mathrm{CaO}-\mathrm{MgO}$ composite layer which suppressed the grain boundary evaporation of $\mathrm{Mg}$. It was also reported that the addition of the Ca element provided improvement in creep resistance properties, and the addition of the Si element increased the yield strength of the alloys (Piyush et al., 2017). Different weight percentage (5\%, 10\%, 15 $\%)$ of Carbon Nano tubes $(\mathrm{CNT})$ and Titanium di Boride $\left(\mathrm{TiB}_{2}\right)$ particles applied to AZ91D grade magnesium increased the hardness and elongation of the material (Velmurugan and Mohan, 2021). Magnesium alloy sheets have low weight and high damping capacity. Therefore, magnesium alloy sheets can be a convenient option for the automotive and aerospace industries. However, low ductility and poor formability properties hinder the commercial production of magnesium sheets. The use of magnesium alloys in the automotive industry has been increased significantly to reduce vehicle weight and $\mathrm{CO}_{2}$ emissions which, in turn, increased fuel economy. However, the usage rate of magnesium is still rather limited since aluminum has already been used widely in automotive applications (Hirsch and AlSamman, 2013). Casting is the main method of producing Mg alloys and represents more than $95 \%$ of the structural applications of magnesium. In recent years, most development has been focused on thin-wall die casting applications in the automotive industry (Luo, 2013), and thin roll-casting of magnesium alloys to produce wide and thin sheets is still an area of study. The different process parameters such as pouring temperature, heat transfer coefficient between 
roll/plate contact interfaces, and casting speed affect the roll-casting process of wide sheet magnesium alloys (Hu et al., 2015). There are a number of studies in the literature regarding the rolling behavior of magnesium. In these studies, cold, warm, and hot rolling of magnesium were realized. Studies have showed that the deformation rates of the rolling process, the rolling temperature, and the number of passes have a substantial effect on the microstructure and mechanical properties of the material. Mao et al. (2012) studied the effect of temperature, passes, and deformation rates on the microstructure and mechanical properties of cast-rolled magnesium strip. Guo et al. (2015) worked on the microstructure and the grain refinement of the hot rolled AZ31 magnesium alloy sheets. They analyzed the surface texture of the sheets not only on the surface layer but also middle layer. Chaudry et al. (2019) studied the dynamic recrystallization behavior of AZ31-0.5Ca magnesium alloy during warm rolling. Nag et al. (2019) produced AZ31 strips by Melt Conditioning Twin Roll Casting process and cold rolling. They carried out detailed microstructural analysis of cold rolled samples.

Over the last few decades, many numerical and experimental studies have been performed to determine the forming parameters of magnesium sheets. In these studies, the formability of magnesium sheets was investigated in terms of the deep drawing, forming, and groove pressing processes at room temperature and under warm forming conditions. Yi et al. (2010) examined the effect of the initial texture of magnesium (AZ31 and ZE10) sheets on the mechanical response, anisotropy, and the formability, by using tensile and round cup drawing tests. Mori and Tsuji (2007) examined the effects of the process parameters such as the lubricant, the clearance and the punch corner radius on the drawability of the commercial AZ31 magnesium alloy sheets and the limiting drawing ratio (LDR) of 1.75 was attained. The LDR can reach 2.0 at the forming temperature of $150{ }^{\circ} \mathrm{C}$ and the drawing velocity of $15 \mathrm{~mm} / \mathrm{s}$ (Chang et al., 2007). Wang et al. (2019) developed an experimental setup for constrained groove pressing (CGP) process. The CGP processes of AZ31 magnesium alloy sheets were performed at elevated temperatures. Additionally, using local heating and cooling techniques and variable blank holder pressure (BHP) improved the formability of magnesium (Yoshihara et al., 2003). The inverse analysis method can be used for determining the formability of 
magnesium alloys at various temperatures by using different forming parameters such as the blank holder forces, initial thickness, and friction coefficient (Nguyen and Bapanapalli, 2009). Blanking operations involve elastic deformation, plastic deformation, and a fracture of sheetmetal between the punch and die. It is extremely important to achieve good edge quality in blanking operations. The clearance and the punch angle are the parameters that most influence the blanking force and edge quality of the parts. Reduction in the clearance value, causes increasing the smooth-sheared area and punching force. However, the roll over depth decreases (Tekiner et al., 2006). On the other hand, increasing clearance value enhances the burr height and negatively affects the quality of the product obtained (Çavuşoğlu and Gürün, 2016). The sheet material thickness is also an important parameter that affects burr formation and blanking force (Çavuşoğlu and Gürün, 2017). In industrial applications, selection of the punch shape depends on the intended use of the obtained parts. According to the usage condition of the falling part, flat-ended punches are preferred for blanking operations while concave, convex, and angled punches can be used for piercing operations. Gürün et al. (2016) performed blanking experiments by using five different punches. The shear angles of the punches were $0^{\circ}, 2^{\circ}, 4^{\circ}, 8^{\circ}$, and $16^{\circ}$, respectively. The blanking forces were reduced approximately $80 \%$ by using the $16^{\circ}$ angled punch. Besides, cutting forces can be reduced significantly by using the convex punch geometry (Kutuniva et al., 2012). The blanking of magnesium alloy sheets at room temperature results in sheared edge defects such as microcracks, loose particles, and a jagged-plus-curved fracture profile. However, such deformities can be suppressed by a rise in temperature (Fazily et al., 2019). The fracture zone becomes comparably more consistent at high temperatures. A rise in temperature results in an increase in the dimensions of the shear band. For this reason, an elevated temperature provides more precise blanks and improves the blanked edge quality (Fazily et al., 2018).

The cutting of sheet materials by punching obtained by rolling method is used in the manufacture of many products in the industry such as automotive parts, aviation industry, 
household appliances and medical materials. The use of magnesium sheet materials has become widespread in the manufacture of body parts in the automotive industry in recent years due to the need to reduce vehicle weights. In this study, AZ61 and AM60 alloys were produced by using an electric resistance furnace. The magnesium alloys manufactured were rolled by two different speeds, $2.5 \mathrm{~m} / \mathrm{min}$ and $7.5 \mathrm{~m} / \mathrm{min}$, respectively. Magnesium sheets 3 mm thick were obtained. The effects of the material and rolling conditions on the blanking forces and part qualities were studied experimentally depending on the punch shape. Three punches with different shapes were used to determine the effect of the punch shape.

\section{MATERIALS AND METHODS}

AZ61 and AM60 alloys were utilized in the experiments. These materials were produced in an electric resistance furnace under the protection of argon gas. Commercial pure $\mathrm{Mg}, \mathrm{Al}$, and $\mathrm{Zn}$ metals and $\mathrm{Mg}-10 \mathrm{wt} \% \mathrm{Mn}$ master alloys were melted at $775^{\circ} \mathrm{C}$. The alloying elements were added to the melted pure $\mathrm{Mg}$ alloy after one hour waiting. The melt was injected into a steel mold after 30 minutes at a temperature of $350^{\circ} \mathrm{C}$ under low 2-3 atm pressure and protection $\mathrm{CO}_{2}+1$ vol\% $\mathrm{SF}_{6}$ mixed gas. Chemical properties of the produced alloys were determined by XRF (Rigaku ZSX Primus II), and they are provided in Table 1.

Table 1 Chemical properties of alloys produced (wt. \%)

\begin{tabular}{|l|l|l|l|l|}
\hline Alloys & Al & Zn & Mn & Mg \\
\hline AZ61 & 5.95 & 1.05 & 0.0032 & Bal \\
\hline AM60 & 6.11 & 0.0045 & 0.38 & Bal \\
\hline
\end{tabular}

The homogenization treatment was conducted at $400^{\circ} \mathrm{C}$ for 24 hours. The rolling billets were manufactured from the cast ingots $12 \times 36 \times 60 \mathrm{~mm}$ in size. The billets were preheated to $450^{\circ} \mathrm{C}$ for30 $\mathrm{min}$ before the rolling process, and this heat treatment was repeated for 5 min between all passes. The rollers were neither heated nor lubricated. The applied rolling schedule is given in Table 2. After the last pass, the sheets with the thickness of $3 \mathrm{~mm}$ were air-cooled. The total reduction in thickness was $83 \%$. Two different rolling speeds, $2.5 \mathrm{~m} / \mathrm{min}$ and 7.5 $\mathrm{m} / \mathrm{min}$, were applied with a $15 \%$ reduction. 
The terms AZ25 and AM25 were used as abbreviations for the rolled AZ61 and AM60 materials with a $2.5 \mathrm{~m} / \mathrm{min}$ rolling speed, respectively. Likewise, the terms AZ75 and AM75 were used as abbreviations for the rolled AZ61 and AM60 materials with a $7.5 \mathrm{~m} / \mathrm{min}$ rolling speed, respectively.

Table 2 Applied Rolling Schedule

\begin{tabular}{|c|c|c|c|c|c|}
\hline $\begin{array}{c}\text { Rolling } \\
\text { Temp }\left({ }^{\circ} \mathbf{C}\right)\end{array}$ & $\begin{array}{c}\text { Reduction } \\
\text { per pass } \\
(\% \pm 2)\end{array}$ & $\begin{array}{l}\text { Rolling } \\
\text { speed } \\
\text { (m/min) }\end{array}$ & $\begin{array}{c}\text { Total } \\
\text { number of } \\
\text { passes }\end{array}$ & $\begin{array}{c}\text { Total } \\
\text { reduction } \\
(\%)\end{array}$ & $\begin{array}{l}\text { First-Final } \\
\text { thickness } \\
(\mathbf{m m})\end{array}$ \\
\hline 400 & 15 & 2.5 & 9 & 75 & $12-3$ \\
\hline 400 & 15 & 7.5 & 9 & 75 & $12-3$ \\
\hline
\end{tabular}

To obtain the best product quality and with the minimum required force required for the blanking/piercing of the magnesium alloys, three punches cut with different cutting edges and the best clearance value selected according to the previous studies were used (Tekiner et al., 2006, Çavuşoğlu and Gürün, 2016, Çavuşoğlu and Gürün, 2017). Blanking forces were obtained by using a load cell which had a a120 kN capacity and 10000 data/sec data reading speed. The data reading speed was adjusted to 2000 data/sec. The experimental results were transferred to a computer by the load cell, data acquisition card, amplifier, and data display software. The signals generated by the load cell were strengthened by using an amplifier to enhance the accuracy of the obtained measurements. A digital analog converter was used to transmit the amplified signals to the computer. The experimental setup is presented in Figure 1.

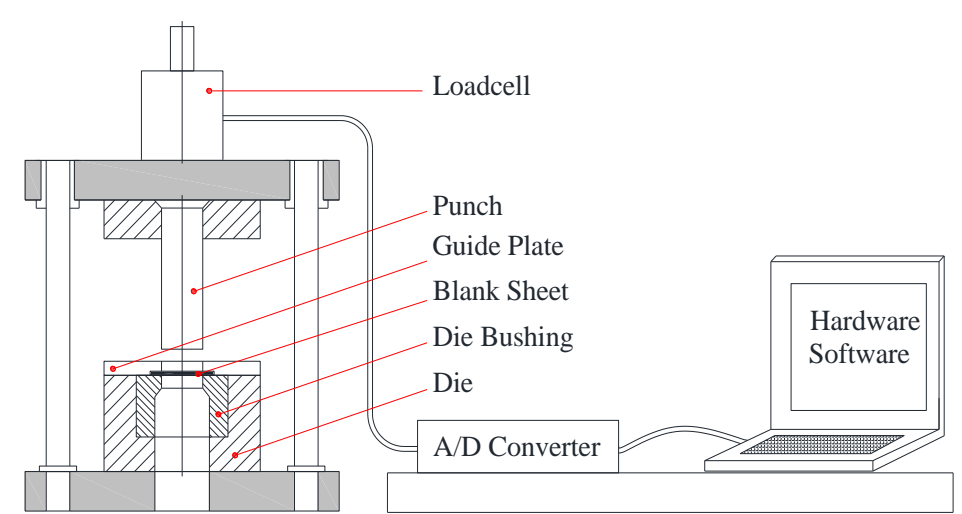

Figure 1 Schematic overview of the experimental setup 
Three punches having different cutting-edge shapes were used in the experiments. The cutting edges of the punches were cut by wire EDM as flat-ended $\left(0^{\circ}\right)$, concave shaped $(\mathrm{R})$, and angled $\left(16^{\circ}\right)$. The punches used in the experiments and the shapes of the falling parts are given in Figure 2.

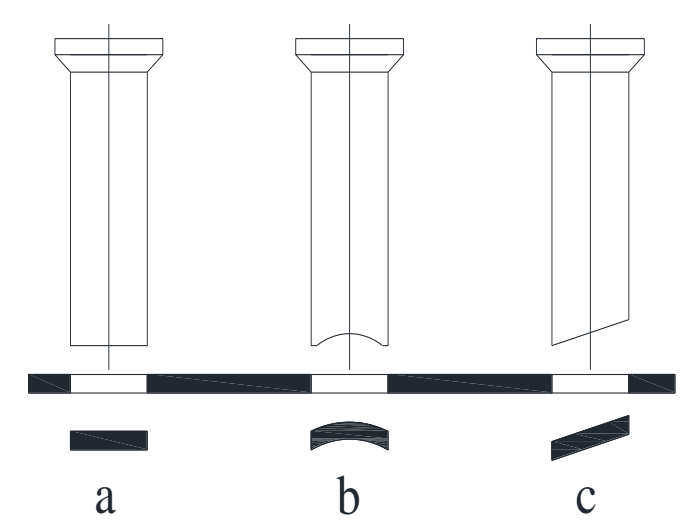

Figure 2 The punches used in the experiments and shapes of the falling parts

Tensile tests were done to evaluate the deformation behaviors of the different magnesium sheet manufactured alloys. Tensile test graphs of the two kinds of material casted are given in Figure 3 as AZ casting (AZ61) and AM casting (AM60). Similarly, the test graphs of the rolled AZ61 and AM60 materials are given as AM25, AZ25, AM75, and AZ75 for the 2.5 $\mathrm{m} / \mathrm{min}$ and $7.5 \mathrm{~m} / \mathrm{min}$ rolling speeds, respectively.

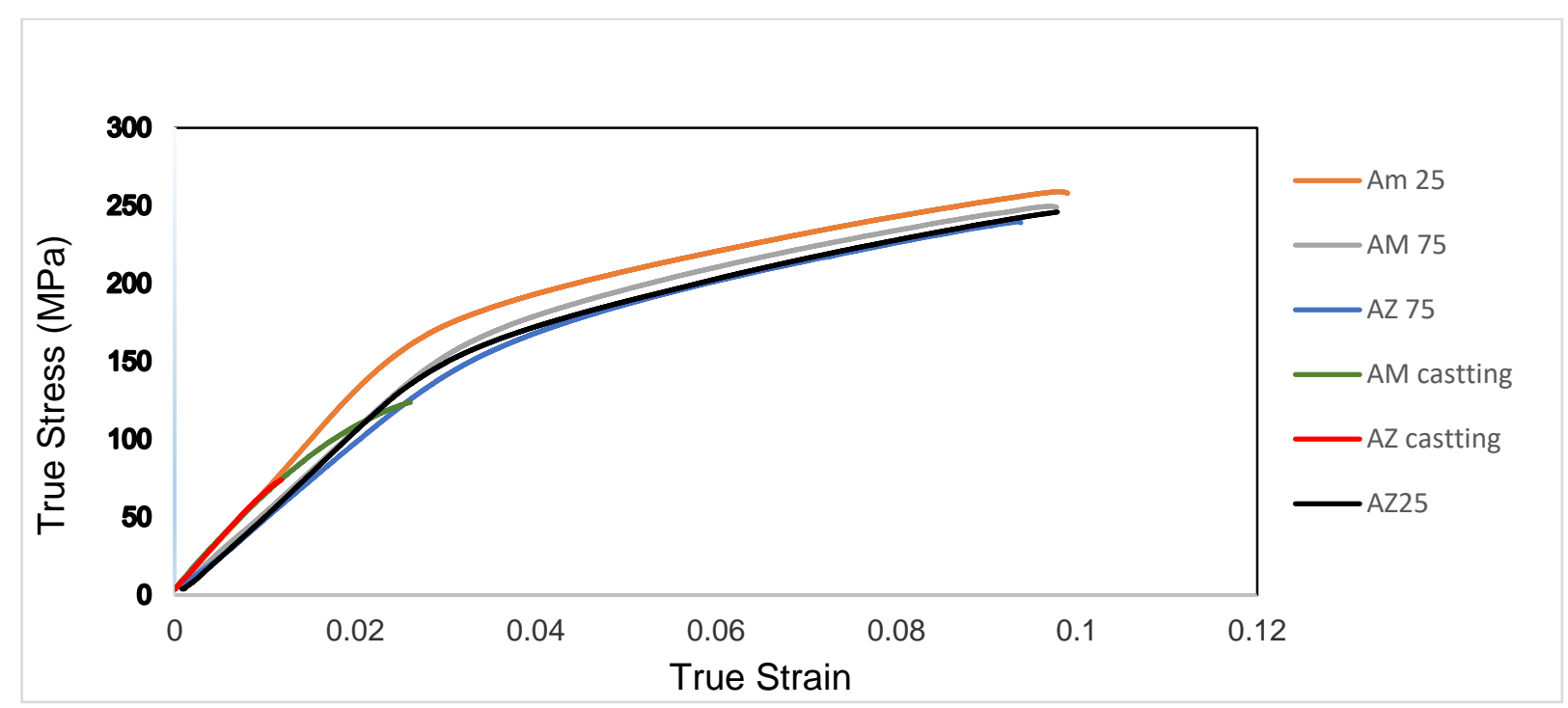

Figure 3 Tensile test results for manufactured mg sheet alloys 
Stereo microscopy was employed to analyze the cross sections and sheared surfaces of samples after punching.

\section{EXPERIMENTAL STUDY}

Blanking experiments were conducted by using three punches having different cutting edges with a constant clearance value of $0.07 \mathrm{~mm}$. The results showed that the blanking force was significantly affected by the punch shape and rolling speed (Figure 4). The lowest blanking forces were observed in the use of the angled punch $\left(16^{\circ}\right)$. The higher blanking forces were measured with the concave shaped punch compared to the angled one. The highest blanking forces were measured during the use of the flat-ended punch. It was also observed that the lowest blanking forces were obtained while blanking of the cast magnesium alloy for all punch types. The blanking force of the AM60 magnesium alloy was higher than the blanking force of the AZ61 magnesium alloy. This indicated that the strength of the AM60 alloy to shearing was higher than the strength of AZ61 alloy.

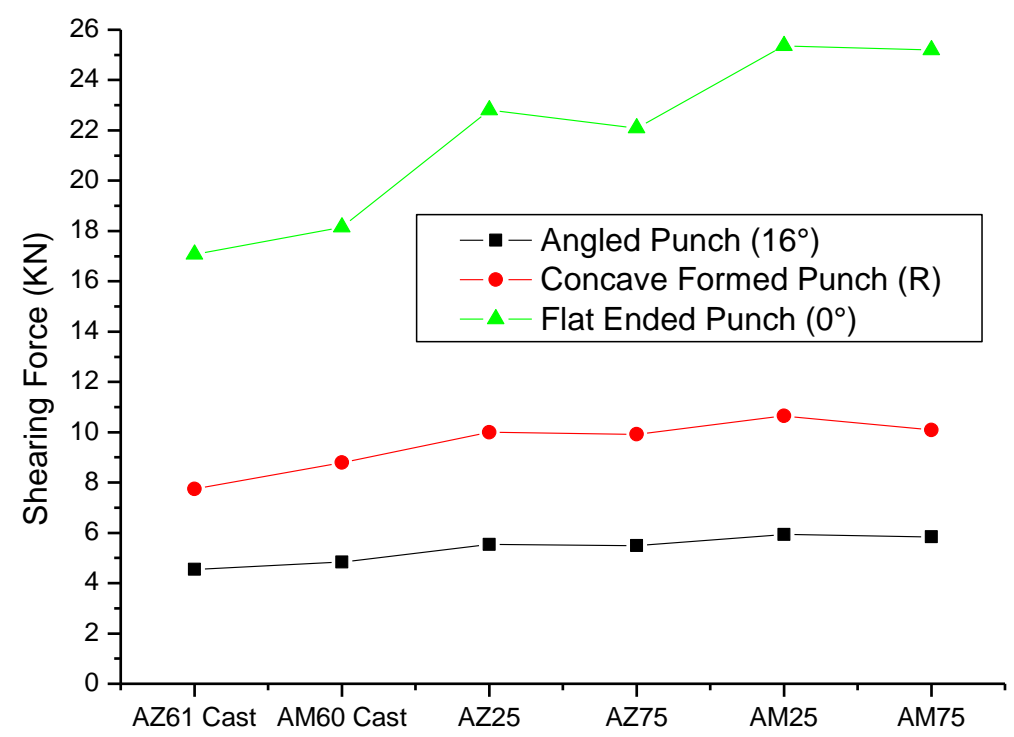

Figure 4 Blanking forces according to the punch shape and material

The results of the flat-ended punch were selected to compare the punching force in the magnesium alloy. The results in this shape of punch were more obvious than in the other 
punch shapes due to the large shearing area exposed to the blanking/piercing operations. The blanking forces measured less in the casted magnesium alloys than in the rolled magnesium alloys. It was obvious that the strength of the rolling magnesium alloy was higher than the strength of the cast magnesium alloys. Comparing the rolled magnesium alloys showed that the AM60 required a higher blanking force than the AZ61. The rollover depth, smooth sheared depth, and fracture depth obtained by the cut samples are given in Table 3. These results were taken from the measurements of the rolled $(2.5 \mathrm{~m} / \mathrm{min})$ and cast magnesium alloys.

Table 3 Rollover Depth, Smooth Sheared Depth, Burr Height, and Fracture Depth

\begin{tabular}{|l|c|c|c|c|c|}
\hline & $\begin{array}{c}\text { Punch } \\
\text { Shape }\end{array}$ & $\begin{array}{c}\text { Rollover } \\
\text { depth, } \mathbf{m m}\end{array}$ & $\begin{array}{c}\text { Smooth sheared } \\
\text { depth, } \mathbf{~ m m}\end{array}$ & $\begin{array}{c}\text { Fracture } \\
\text { depth, } \mathbf{~ m m}\end{array}$ & $\begin{array}{c}\text { Burr } \\
\text { height, } \mathbf{~ m m}\end{array}$ \\
\hline AM casting & $0^{\mathbf{o}}$ & 0.2 & 1.1 & 1.7 & 0.09 \\
\hline AM 25 & $0^{\mathbf{o}}$ & 0.2 & 1.4 & 1.4 & 0.05 \\
\hline AM casting & $\mathrm{R}$ & 0.3 & 1.35 & 1.35 & 0.1 \\
\hline AM 25 & $\mathrm{R}$ & 0.3 & 1.3 & 1.4 & 0.05 \\
\hline AZ casting & $0^{\mathbf{o}}$ & 0.27 & 1.03 & 1.7 & 0.08 \\
\hline AZ 25 & $0^{\mathbf{o}}$ & 0.17 & 1.43 & 1.4 & 0.05 \\
\hline AZ casting & $\mathrm{R}$ & 0.22 & 1.1 & 1.68 & 0.07 \\
\hline AZ 25 & $\mathrm{R}$ & 0.35 & 1.25 & 1.4 & 0.05 \\
\hline
\end{tabular}

The measurements obtained from the cut parts by using flat-ended and concave punches were also compared. The depth zones gained from the flat-ended and concave punches are given in Figure 5 and Figure 6, respectively.

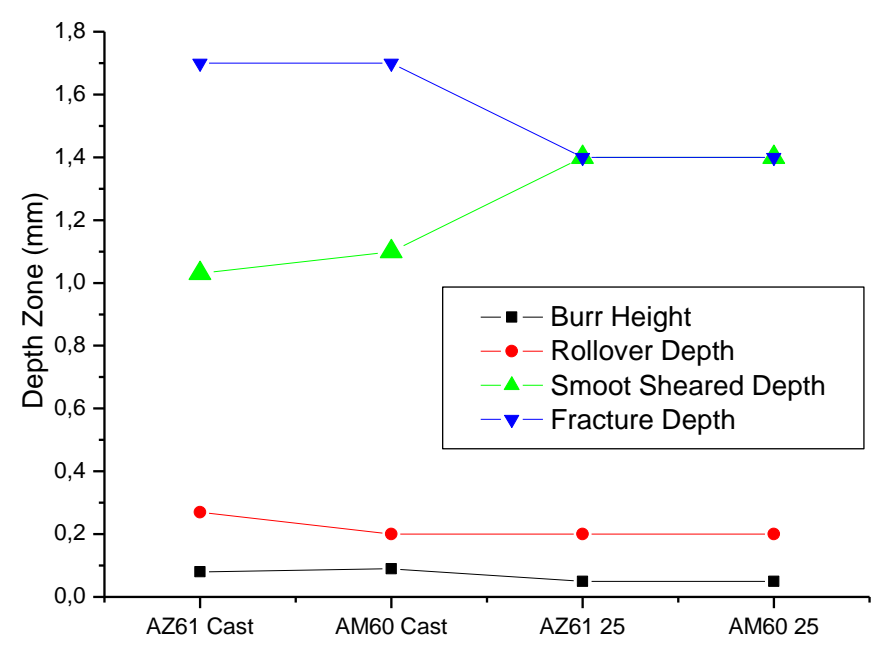

Figure 5 Depth zones for different mg alloys gained from using flat-ended punch 


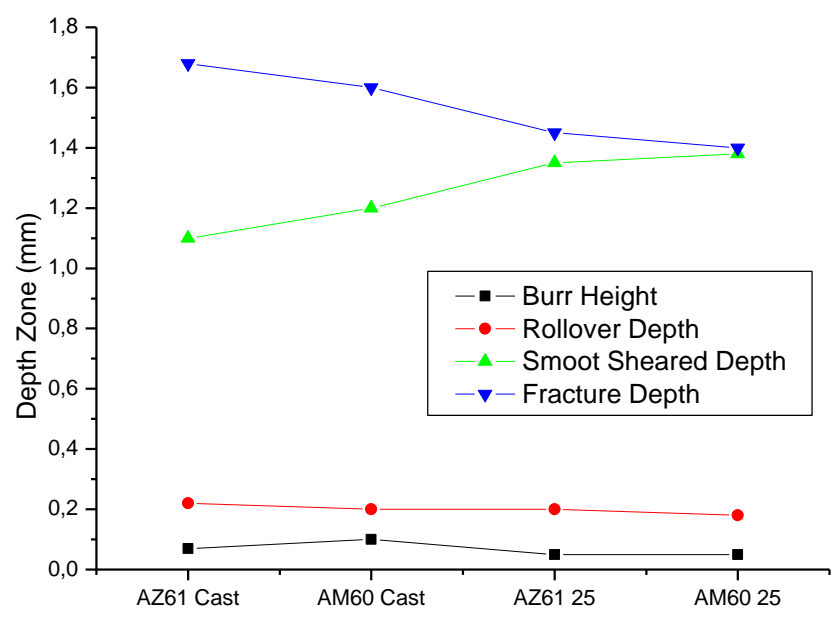

Figure 6 Depth zones for different mg alloys gained from using concave shaped punch

On every blanking, some amount of burr occurs according to the type of material or alloys used. Penetration increases as the flow of specialized soft materials increases. Thus, the burr was higher in the casting alloys than the rolling alloys because the casting alloys were softer than the rolling alloys. In this respect, it can be concluded that the smooth surface increases as the material hardening increases.
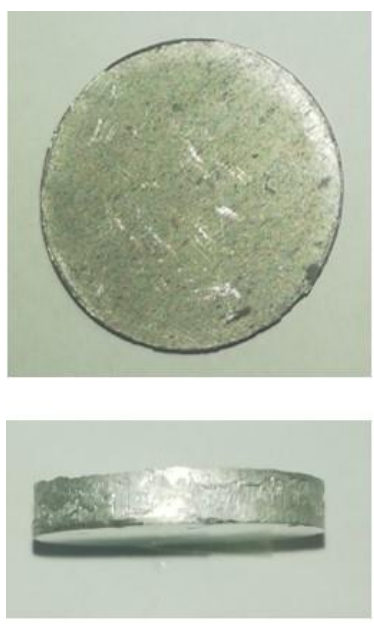

a).Flat-ended
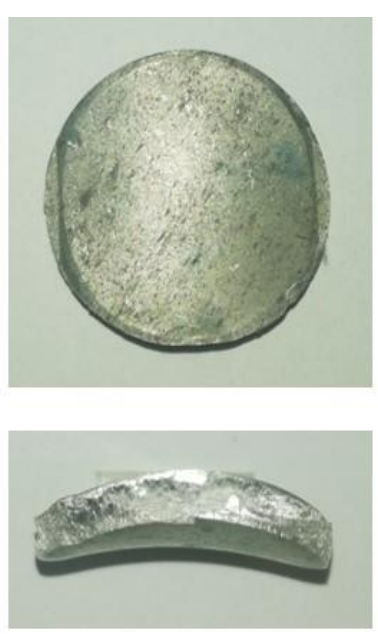

b).Concave-shaped
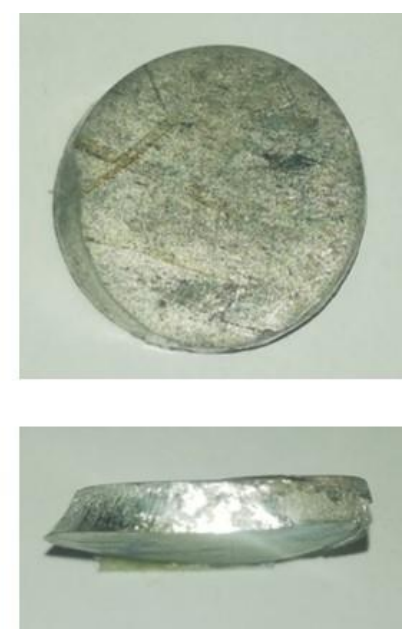

c) Angled

Figure 7 Side profile shapes of the falling parts obtained by using various punches

In the experiments using the flat-ended punches, the side profile shapes of the falling parts were linear. However, the side profile shapes of the falling parts obtained using concave shaped and angled punches were not linear (Figure 7). Therefore, it was very difficult to ensure the dimensional accuracy of the falling parts in the using of concave shape and angled 
punches. The cutting edge shapes of these punches caused negative effects on the edge quality of the blanks and falling parts, as previously reported (Gürün et al., 2016, Kutuniva et al., 2012). The blanked part shape was obtained as planar in the use of all punches. For this reason, it is convenient that the flat-ended punches can be used just for the blanking processes, while all three types of punches can be used for piercing.

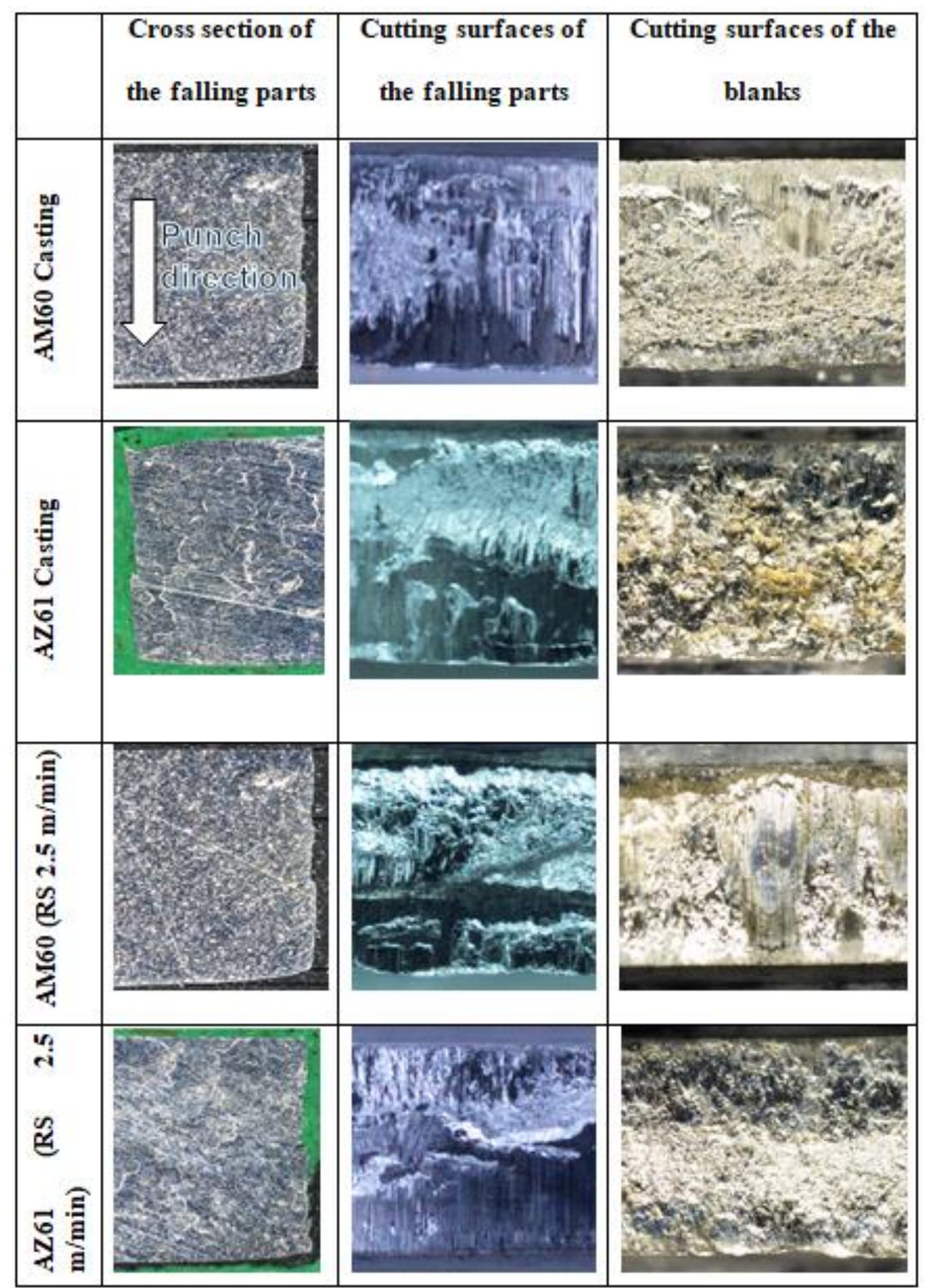

Figure 8 Stereo microscope images taken from cross sections and sheared surfaces of samples after blanking using flat-ended punch $\left(0^{\circ}\right)$ 
During the blanking process of the AM60 and AZ61 sheets, many micro cracks parallel to the sheet plane were observed in the shearing zone. These micro-cracks reduced the strength and quality of the parts. In the blanking of the rolled AM60 and AZ61 Mg sheets, the qualities of the sheared surfaces significantly improved in all samples. Figure 8 shows the sheared edge profiles of the sheets produced by using casting and rolling. As shown in Figure 8, the smooth sheared depth in the rolling alloys was higher than in the casting alloys, and the fracture area in the casting samples was bigger than the rolled samples. However, the fracture depth was bigger in the blanking of a soft material than a hard material. Therefore, according to the experimental results, it can be said that increasing the rolling rates and the number of the rolling passes positively affected quality of the resulting product.

\section{CONCLUSION}

In this study, the effects of various punches having different cutting edges on blanking force in the blanking/piercing process were examined experimentally. The ingot magnesium materials were produced by casting. These ingots were machined to the required dimensions and gradually rolled up to $3 \mathrm{~mm}$ thickness. The punches used in the experiments were machined by using a wire EDM as flat-ended, concave shaped, and $16^{\circ}$ angled.

As a result of this study, the following conclusions can be drawn:

1- The lowest blanking forces were observed in the using of the angled punch $\left(16^{\circ}\right)$ during the experiments. The highest value of this force was observed in the using of the flat-ended punch $\left(0^{\circ}\right)$

2- The blanking force in cast magnesium alloys is less than in the rolled magnesium alloys because of its lower hardness value. However, the smooth shear fracture rate decreased in the blanking of the cast alloys. This situation negatively affected the quality of the obtained products. 
3- Rolled AM60 alloy required more shearing force than rolled AZ61 alloy. This means that the shear resistance of the AM 60 was higher than the AZ61.

4- As the hardness of the material increased, the smooth sheared depth also increased. Conversely, the hardness of the material decreased the rollover depth, fracture depth, and burr height. Therefore, it can be said that increasing rolling rates and number of the applied passes positively affected the quality of the obtained product due to the increased hardness values.

5- Depending on the side profile shape of the falling part, it is suitable to use just flat-ended punches for blanking while all three punches can be used for piercing.

\section{REFERENCES}

Chang, Q.F., Li, D.Y., Peng, Y.H., Zeng, X.Q. 2007. Experimental and numerical study of warm deep drawing of AZ31 magnesium alloy sheet. International Journal of Machine Tools \& Manufacture 47: 436-443. DOI:10.1016/j.ijmachtools.2006.06.013

Chaudry, U.M., Kim, T.H., Kim, Y.S., Hamad, K., Ko, Y.G., Kim, J.G. 2019. Dynamic recrystallization behavior of AZ31-0.5Ca magnesium alloy during warm rolling. Materials Science \& Engineering A 762: 1-6. DOI: 10.1016/j.msea.2019.138085

Çavuşoğlu, O., Gürün, H. 2016. Investigation and fuzzy logic prediction of the effects of clearance on the banking process of CuZn30 sheet metal. Kovove Mater. 54: 125-131. DOI: $10.4149 / \mathrm{km} 20162125$

Çavuşoğlu, O., Gürün, H. 2017. The relationship of burr height and blanking force with clearance in the blanking process of AA5754 aluminium alloy. Transactions of Famena 41: 55-62. DOI: $10.21278 /$ TOF.41105

Fazily, P., Yu, J., Lee, C.W. 2018. Finite Element Analysis of Blanking Operation of Magnesium Alloy (AZ31) Sheet Using Ductile Fracture Criteria and Its Experimental Verification at Various Temperatures. IOP Conf. Series: Journal of Physics: Conf. Series 1063, 012158. DOI :10.1088/1742-6596/1063/1/012158 
Fazily, P., Yu, J., Lee, C.W. 2019. Characterization of Sheared Edges in Warm Blanking of Magnesium Alloy AZ31B. Materials 12: 1-16. DOI:10.3390/ma12071023

Guo, F., Zhang, D.F., Yang, X.S., Jiang, L.Y., Pan, F.S. 2015. Microstructure and texture evolution of AZ31 magnesium alloy during large strain hot rolling. Trans. Nonferrous Met. Soc. China 25: 14-21. DOI: 10.1016/S1003-6326(15)63573-7

Gürün, H., Göktaş, M., Güldaş, A. 2016. Experimental examination of effects of punch angle and clearance on shearing force and estimation of shearing force using fuzzy logic. Transactions of Famena 40: 19-28. DOI: 10.21278/TOF.40302

Hirsch, J., Al-Samman, T. 2013. Superior light metals by texture engineering: Optimized aluminum and magnesium alloys for automotive applications. Acta Materialia 61: 818-843. DOI: 10.1016/j.actamat.2012.10.044

Hu, H.J., Li, Y.Y., Dai, J.L. 2015. Relationships between process parameters and temperature field of roll casting for wide sheet made of AZ61 magnesium alloy: Finite element method. Russ. J. Non-ferrous Metals 56:33-38. DOI:10.3103/S1067821215010101

Kumar, D.S., Sasanka, C.T., Ravindra, K., Suman, K.N.S. 2015. Magnesium and its alloys in automotive applications - A review. Am. J. Mater. Sci. Technol. 4: 12-30. DOI:10.7726/ajmst.2015.1002

Kutuniva, K., Karjalainen, J.A., Mäntyjärvi. K. 2012. Effect of convex sheared punch geometry on cutting force of ultra-high-strength steel. Key Engineering Materials 504-506: 1359-1364. DOI:10.4028/www.scientific.net/KEM.504-506.1359

Luo, A.A. 2013. Magnesium casting technology for structural applications. Journal of Magnesium and Alloys 1: 2-22. DOI: 10.1016/j.jma.2013.02.002 
Mao, D., Zhang, B., Li, J., Li, Z., Shi, C. 2012. Effect of hot-rolling and warm-rolling process on properties of cast-rolling AZ31B magnesium alloy strip. Procedia Engineering 27: 887-894.

Mori, K., Tsuji, H. 2007. Cold Deep Drawing of Commercial Magnesium Alloy Sheets. Annals of the CIRP 56: 285-288. DOI:10.1016/j.cirp.2007.05.066

Nag, A., Kota, P., Agrawal, N., Bhandari, A., Singh, N., Ray, P., Patil, P., Das, S. 2019. An investigation of the cold rolled AZ31 alloy strip produced by MC-TRC process. Materials Letters 240: 295-298. DOI: 10.1016/j.matlet.2019.01.008

Nguyen, B.N., Bapanapalli, S.K. 2009. Forming analysis of AZ31 magnesium alloy sheets by means of a multistep inverse approach. Materials and Design 30: 992-999. DOI:10.1016/j.matdes.2008.06.052

Piyush, E., Raghu, R., Rakesh, M.S., Sriram, S.G. 2017. Magnesium alloy casting technology for automotive applications - A review. International Research Journal of Engineering and Technology 4: 675-681.

Tekiner, Z., Nalbant, M., Gürün, H. 2006. An experimental study for the effect of different clearances on burr, smooth-sheared and blanking force on aluminium sheet metal. Materials and Design 27: 1134-1138. DOI:10.1016/j.matdes.2005.03.013

Wang, Z., Guan, Y., Wang, T., Zhang, Q., Wei, X., Fang, X., Zhu, G., Gao, S. 2019. Microstructure and mechanical properties of AZ31 magnesium alloy sheets processed by constrained groove pressing. Materials Science \& Engineering A 745: 450-459. DOI:10.1016/j.msea.2019.01.006

Velmurugan, V., Mohan, B. 2021. Effect of $\mathrm{CNT}_{\mathrm{T}} \mathrm{TiB}_{2}$ Particle on Mechanical, Metallurgical Behaviour of Magnesium (AZ91D) Composites. Journal of Engg. Research, ICIPPSD Special Issue: 1-10. DOI: 10.36909/jer.ICIPPSD.15529 
Yi, S., Bohlen, J., Heinemann, F., Letzig, D. 2010. Mechanical anisotropy and deep drawing behaviour of AZ31 and ZE10 magnesium alloy sheets. Acta Materialia 58: 592-605. DOI:10.1016/j.actamat.2009.09.038

Yoshihara, S., Yamamoto, H., Manabe, K., Nishimura, H. 2003. Formability enhancement in magnesium alloy deep drawing by local heating and cooling technique. Journal of Materials Processing Technology 143-144: 612-615. DOI:10.1016/S0924-0136(03)004424 